Global Journal of Pure and Applied Mathematics.

ISSN 0973-1768 Volume 11, Number 2 (2015), pp. 777-787

(C) Research India Publications

https://dx.doi.org/10.37622/GJPAM/11.2.2015.777-787

\title{
Optimization of Friction Stir Welding Process Parameters using Taguchi's Method
}

\author{
Vaibhav R. Shinde ${ }^{\mathbf{1}}$, Mandar Sapre ${ }^{\mathbf{2}}$, VijayKumar S. Jatti ${ }^{\mathbf{3}}$ \\ ${ }^{1}$ M.Tech Student, Symbiosis Institute of Technology (SIT), Symbiosis International \\ University (SIU), Lavale, Pune-412 115, Maharashtra State, India \\ ${ }^{2}$ Assistant Professor, Symbiosis Institute of Technology (SIT), Symbiosis International \\ University (SIU), Lavale, Pune-412 115, Maharashtra State, India \\ ${ }^{3}$ Assistant Professor, Symbiosis Institute of Technology (SIT), Symbiosis International \\ University (SIU), Lavale, Pune-412 115, Maharashtra State, India \\ Tel: +91-20-39116300; Fax: +91-20-39116460
}

\begin{abstract}
This study has been conducted to investigate the effect of welding process parameters on the mechanical properties of aluminium alloy HE 30 and HE 9 using friction stir welding (FSW). Different friction stir welded specimens were produced by employing variable welding speed $(16 \mathrm{~mm} / \mathrm{min}, 20$ $\mathrm{mm} / \mathrm{min}$, and $25 \mathrm{~mm} / \mathrm{min}$ ) and tool rotation speed (1000 rpm, $1400 \mathrm{rpm}$, and $2000 \mathrm{rpm}$ ). HE 30 and HE 9 aluminium alloy of $6 \mathrm{~mm}$ thick plates were welded using a taper shaped pin tool made of high carbon high chromium (HCHCr) D2 tool steel. Ultimate tensile strength and hardness tests were performed to evaluate the welding strength at the joints. The experimental results indicate that the welding process parameters have significant effect on properties of the joints. Experiments were carried out as per Taguchi's orthogonal L9 array. Taguchi's signal to noise ratio and analysis of variance methods are used to find out the most significant parameter that affects the ultimate tensile strength and hardness of the weld. From the statistical analysis it was found that spindle speed is the significant process parameter that affects ultimate tensile strength. Whereas spindle speed and welding speed are the significant process parameters that affect hardness. And the optimal parameter setting obtained from Taguchi analysis maximizes the tensile strength and hardness.
\end{abstract}

Keywords: Taguchi's method, HE 30 Al alloy, HE 9 Al alloy, Tensile strength, Hardness, ANOVA. 


\section{Introduction}

Friction stir welding (FSW) is a revolutionary solid state welding technique invented at The Welding Institute (TWI) in 1991. The FSW process operates below the solidus temperature of the metals being joined and hence no melting takes place during the process. This process is a derivative of the conventional friction welding and is being used to produce continuous welded seams for plate fabrication. Since its invention in 1991, continuous attempts have been made by researchers to understand, use and improve this process. FSW is a hot-shear joining process in which a non-consumable, rotating tool plunges into a rigidly clamped work piece and moves along the joint to be welded. The FSW process is initiated by plunging of a rotating tool into the joint until the shoulder contacts the top surface of the work piece. As the tool translates along the joint, heat is generated by rubbing action of tool shoulder against the work piece. Additional heat is generated by visco-plastic dissipation of mechanical energy at high strain rates due to interactions between tool and work piece. The heat thus generated results in thermal softening of the material. The thermally softened material is contained at the underside by a backing plate, at the sides by non-softened parent material, and at the topside by pin force. The softened material is then forced to flow by the translation of the tool from the front to the back of the pin where it cools, consolidates and results in joint formation. FSW process requires a tool of harder material than the work piece material being welded. Squillac et al. investigated the effect of rotational and welding speed on tensile strength and fatigue strength of AA 6056 joints made by FSW. The influence of process parameters on the weld quality was assessed by Analysis of Variance (ANOVA) methods using the experimental results. A complete two factor factorial experiment, with three replicates was performed by the authors. Meng et al. used a multi-targeted optimization with constraint based on genetic algorithm for optimization of stir head dimensions. The objective function employed was an analytically derived mathematical model relating heat input coefficient with tool parameters. The goal of optimization was to determine the shoulder diameter and pin diameter of the stirring tool for maximizing the tensile strength of the friction stir welds of aluminium-lithium alloy. Fratini and Corona investigated FSW lap joint resistance optimization using gradient techniques. They combined the gradient technique and the finite difference method to determine the optimal rotating speed and welding speed in order to maximize the joint strength per unit length. Nandan et al. used genetic algorithm to determine four process parameters by minimizing the difference between the numerical model and experiments. The process parameters included variable friction coefficient, the extent of sticking, the heat transfer coefficient, and the extent of viscous dissipation converted into heat. These selected parameters were optimized by a genetic algorithm using a limited volume of measured temperatures at several monitoring locations during FSW of dissimilar aluminium alloys AA 1200 and AA 6061.Use of Artificial neural network (ANN) was proposed by Okuyucu et al. to obtain correlation between FSW parameters and mechanical properties of aluminium plates. Their attempt was to correlate the parameters rather than to optimize them. The input parameters were weld speed and tool rotational speed while the output parameters included mechanical properties such as tensile strength, elongation, hardness of weld metal and hardness of 
heat affected zone. The obtained model was used to calculate mechanical properties of welded $\mathrm{Al}$ plates as a function of weld speed and rotational speed. Conventional parametric design of experimental approach is cumbersome and requires large number of experimental trials. Statistical techniques are often used to reduce the number of experiments conducted. Lakshmi narayanan et al. used one such statistical technique known as Taguchi technique to determine the effect of three process parameters, i.e. tool rotational speed, traverse speed, and axial force on the tensile strength of friction stir welded RDE-40 aluminium alloy. Jayaraman et al. used a similar technique to find the effect of three process parameters on the tensile strength of friction stir welded A319 aluminium alloy. In both these studies, the authors performed Analysis of Variance (ANOVA) to identify statistically significant process parameters. Taguchi's orthogonal array and analysis of variance was used to identify significant parameters that influence the ultimate tensile strength and hardness. Optimal setting of FSW process parameters was carried out using Taguchi single objective optimization method.

\section{Material and Methods}

In this investigation, aluminium alloy sheets of dissimilar material were welded. Workpiece materials considered for the study are HE 30 and HE $9 \mathrm{Al}$ alloy. The sheet was cut to required size $(175 \mathrm{~mm} \times 125 \mathrm{~mm} \times 6 \mathrm{~mm}$ ) by power hacksaw cutting and followed by grinding to remove the burr. The surfaces of both sheets were cleaned with acetone before the welding process. A conventional milling machine was used as friction stir welding machine (figure 1). Butt joint configuration was used to fabricate the friction stir welds. The joint was initially obtained by securing the plates in position using mechanical clamps. That is clamped on the backing plate which was bolted directly to the bed of the milling machine. The welding speeds and the rotational speeds were achieved manually by setting on machine. The rotational speeds of spindle were $1000 \mathrm{rpm}, 1400 \mathrm{rpm}$ and $2000 \mathrm{rpm}$ and feed rates at 16 $\mathrm{mm} / \mathrm{min}, 20 \mathrm{~mm} / \mathrm{min}$ and $25 \mathrm{~mm} / \mathrm{min}$ were chosen to represent low, medium and high settings respectively. A non-consumable tool made of high carbon high chromium (D2) was used to fabricate the joints. Welding tool with shoulder diameters of $18 \mathrm{~mm}$ and tapered shank were used (figure 2). 


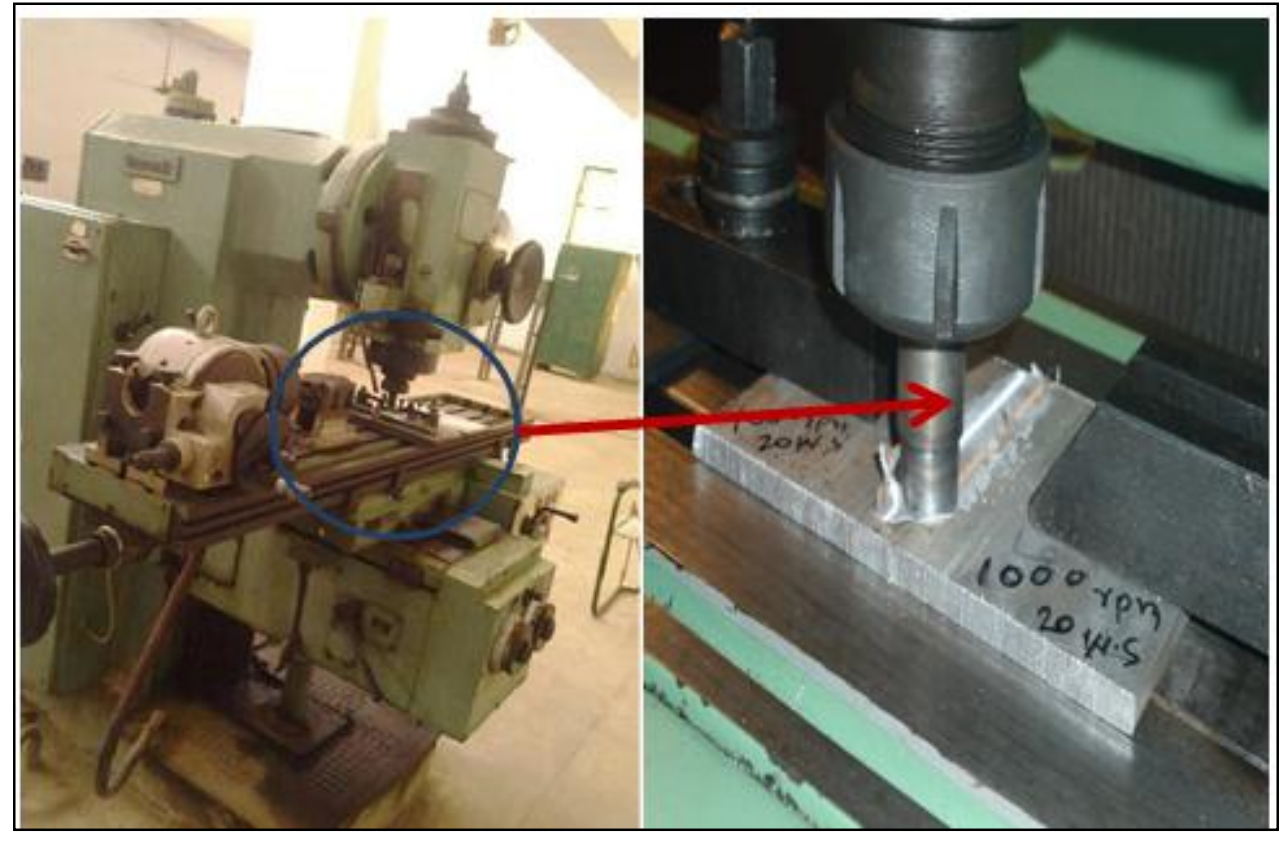

Figure 1: FSW Experimental Setup

For the purpose of minimizing the experimental work, a simple and adequate experimental design named Taguchi's method is used. Experiments were designed using Taguchi's L9 orthogonal array. Table 1 shows the process parameters and their levels and figure 3 shows the workpiece after friction stir welding.

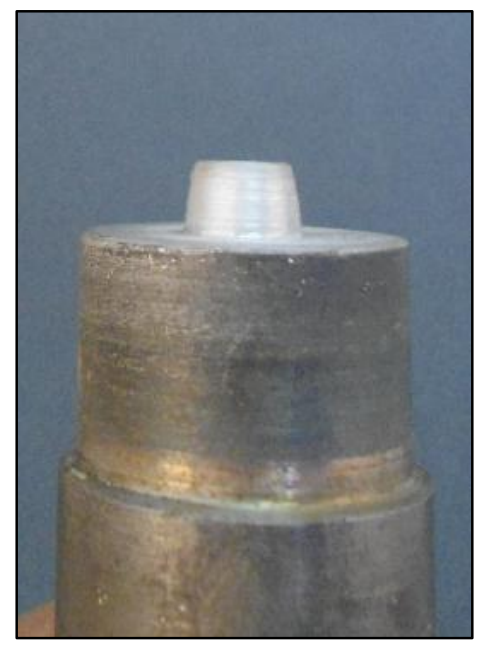

Figure 2: FSW Tool High Carbon High Chromium Grade D2 


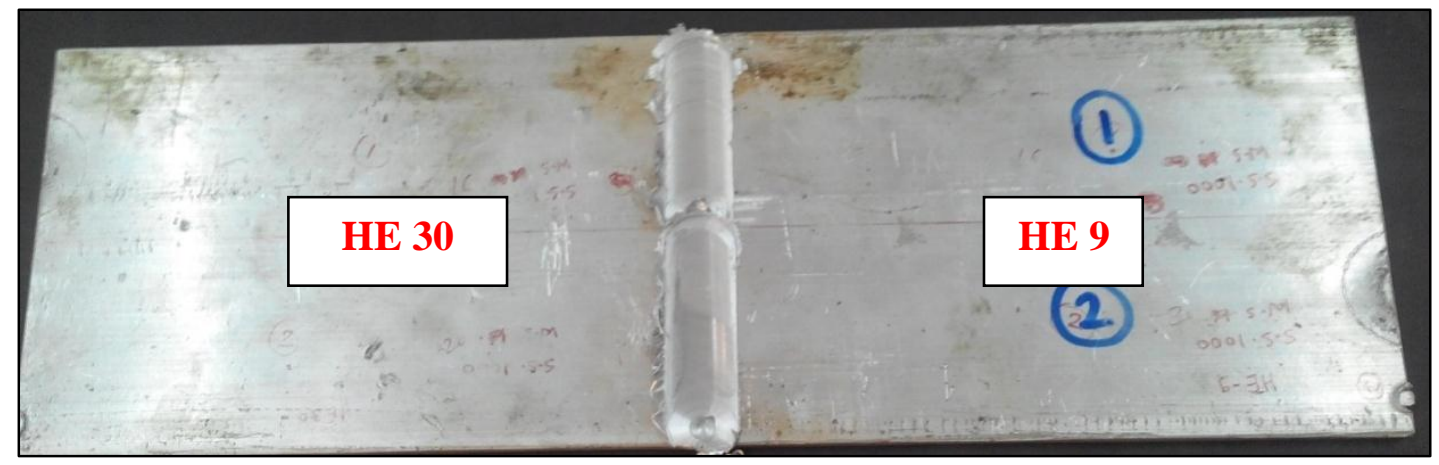

Figure 3: FSW of Aluminium alloy HE30 and HE9

Table 1: FSW process parameters with its levels

\begin{tabular}{|l|l|l|l|l|l|l|}
\hline Sr. No. & Factors & Notation & Units & \multicolumn{3}{|l|}{ Variable / Levels } \\
\hline 1 & Rotational speed & $\mathrm{N}$ & $\mathrm{rpm}$ & 1000 & 1400 & 2000 \\
\hline 2 & Welding speed & $\mathrm{V}$ & $\mathrm{mm} / \mathrm{min}$ & 16 & 20 & 25 \\
\hline 3 & Shoulder diameter & $\mathrm{D}$ & $\mathrm{mm}$ & 18 & & \\
\hline 4 & Plate thickness & $\mathrm{T}$ & $\mathrm{mm}$ & 6 & & \\
\hline 5 & Pin diameter & $\mathrm{D}$ & $\mathrm{mm}$ & 6.5 & & \\
\hline 6 & Pin height & $\mathrm{H}$ & $\mathrm{mm}$ & 5.5 & & \\
\hline
\end{tabular}

The philosophy of Taguchi's method is to minimize the variations in product or systems characteristics. To determine the effect of each variable on the output, the signal-to-noise ratios are calculated for each experimental trial [8, 9]. For this study the quality characteristic is to maximize and the signal-to-noise is calculated using equations 2 .

$$
\mathrm{S} / \mathrm{N}_{\mathrm{i}}=-10 \log _{10}\left[\frac{1}{n} \sum_{j=1}^{n} \frac{1}{y^{2}}\right]
$$

where, $\mathrm{i}=$ experiment number, $\mathrm{j}=$ trial number, $\mathrm{y}=$ observed value, $\mathrm{n}=$ number of trials for experiment $\mathrm{i}[8,9]$.

\section{Results and Discussions}

In order to see the effect of process parameters on ultimate tensile strength and hardness, experiments were conducted using L9 orthogonal array as shown in table 2. The average values of tensile strength for each parameter at levels 1,2 and 3 for $\mathrm{S} / \mathrm{N}$ data are plotted in figure 4 and raw data is plotted in figure 5 . The average values of ultimate tensile strength for each parameter at levels 1,2 and 3 for $\mathrm{S} / \mathrm{N}$ data are plotted in figure 6 and raw data is plotted in figure 7. Analysis of variance (ANOVA) was performed at a confidence level of $95 \%$ i.e. a significance level of 0.05 . It was 
found that spindle speed is the most significant process parameter that affects ultimate tensile strength. Both spindle speed and welding speed affects the hardness. The response table shows the average of each response characteristic for each level of each factor. The tables include ranks based on delta statistics, which compare the relative magnitude of effects. The ranks and the delta values show that spindle speed and welding speed are significant process parameters for tensile strength and hardness. Table 3 and 4 shows the ANOVA table of tensile strength for $\mathrm{S} / \mathrm{N}$ data and raw data respectively. Table 5 and 6 shows the Taguchi response table of tensile strength for $\mathrm{S} / \mathrm{N}$ data and raw data respectively. All the analysis was carried out using MINITAB 15 statistical software.

Table 2: Taguchi experimental design with observed values

\begin{tabular}{|l|l|l|l|}
\hline $\begin{array}{l}\text { Spindle speed } \\
(\mathbf{r p m})\end{array}$ & $\begin{array}{l}\text { Welding speed } \\
(\mathbf{m m} / \mathbf{m i n})\end{array}$ & $\begin{array}{l}\text { Ultimate Tensile } \\
\text { Strength }(\mathbf{M P a})\end{array}$ & $\begin{array}{l}\text { Hardness } \\
(\mathbf{B H N})\end{array}$ \\
\hline 1000 & 16 & 58.74 & 67.85 \\
\hline 1000 & 20 & 63.96 & 68.79 \\
\hline 1000 & 25 & 59.65 & 70.98 \\
\hline 1400 & 16 & 60.65 & 69.1 \\
\hline 1400 & 20 & 59.2 & 69.98 \\
\hline 1400 & 25 & 55.46 & 71.83 \\
\hline 2000 & 16 & 50.39 & 70.95 \\
\hline 2000 & 20 & 52.61 & 72.56 \\
\hline 2000 & 25 & 48.65 & 74.1 \\
\hline
\end{tabular}

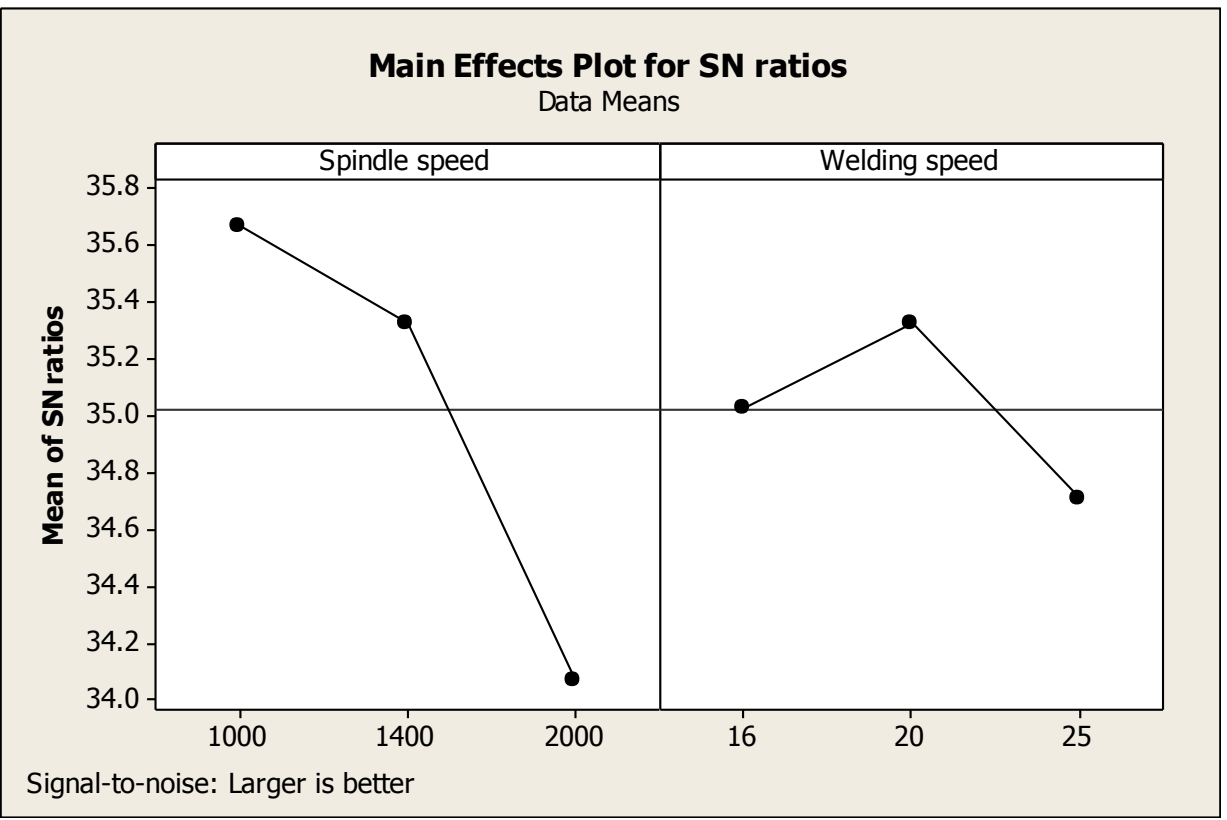

Figure 4: Effect of input parameters on ultimate tensile strength (S/N data) 


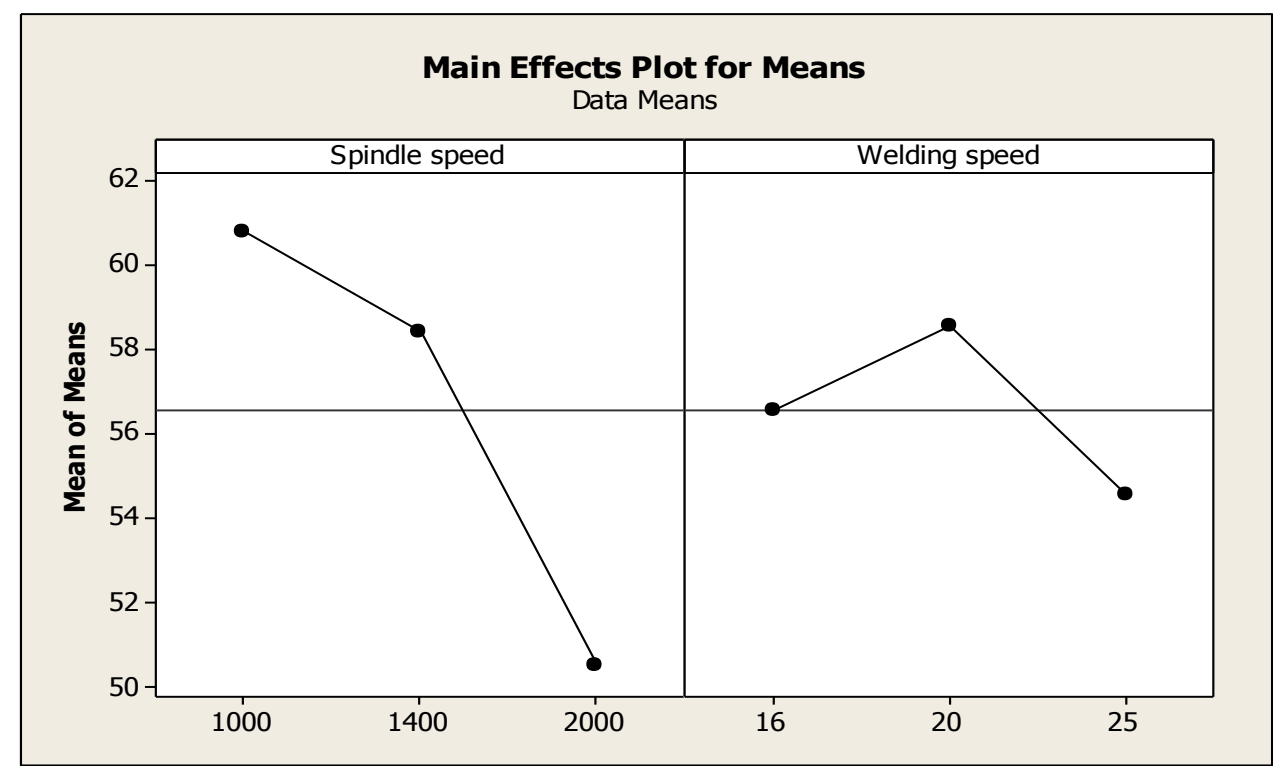

Figure 5: Effect of input parameters on ultimate tensile strength (raw data)

Table 3: ANOVA table for ultimate tensile strength ( $\mathrm{S} / \mathrm{N}$ data)

\begin{tabular}{|lrrrrrrr|}
\hline Source & DF & Seq SS & Adj SS & Adj MS & F & P \\
\hline Spindle speed & 2 & 4.2577 & 4.2577 & 2.12883 & 29.02 & 0.004 \\
\hline Welding speed & 2 & 0.5721 & 0.5721 & 0.28604 & 3.90 & 0.115 \\
\hline Residual Error & 4 & 0.2934 & 0.2934 & 0.07336 & & \\
\hline Total & 8 & 5.1232 & & & \\
\hline S $=0.2708 \quad$ R-Sq $=94.3 \%$ & R-Sq (adj) $=88.5 \%$ & \\
\hline
\end{tabular}

Table 4: ANOVA table for ultimate tensile strength (raw data)

\begin{tabular}{|lrrrrrrr|}
\hline Source & DF & Seq SS & Adj SS & Adj MS & F & P \\
\hline Epindle speed & 2 & 172.43 & 172.43 & 86.214 & 25.11 & 0.005 \\
\hline Nelding speed & 2 & 24.04 & 24.04 & 12.020 & 3.50 & 0.132 \\
\hline Residual Error & 4 & 13.73 & 13.73 & 3.433 & & \\
\hline Total & 8 & 210.20 & & & \\
\hline S $=1.853$ & R-Sq $=93.58$ & R-Sq $($ adj $)=86.98$ \\
\hline
\end{tabular}


Table 5: Response table for ultimate tensile strength ( $\mathrm{S} / \mathrm{N}$ ratio data, Larger-thebetter)

\begin{tabular}{|lrr|}
\hline & Spindle & Welding \\
\hline Level & speed & speed \\
\hline 1 & 35.67 & 35.03 \\
\hline 2 & 35.33 & 35.33 \\
\hline 3 & 34.07 & 34.71 \\
\hline Delta & 1.60 & 0.62 \\
\hline Rank & 1 & 2 \\
\hline
\end{tabular}

Table 6: Response table for ultimate tensile strength (raw data)

\begin{tabular}{|lcc|}
\hline \multicolumn{3}{|l|}{ Response Table for Means } \\
\hline & Spindle & Welding \\
\hline Level & speed & speed \\
\hline 1 & 60.78 & 56.59 \\
\hline 2 & 58.44 & 58.59 \\
\hline 3 & 50.55 & 54.59 \\
\hline Delta & 10.23 & 4.00 \\
\hline Rank & 1 & 2 \\
\hline \hline
\end{tabular}

From figure 4 and 5 it can be concluded that for achieving maximum ultimate tensile strength the optimal setting is spindle speed of $1000 \mathrm{rpm}$ and welding speed of $20 \mathrm{~mm} / \mathrm{min}$. Table 7 and 8 shows the ANOVA table of hardness for S/N data and raw data respectively. Table 9 and 10 shows the Taguchi response table of hardness for $\mathrm{S} / \mathrm{N}$ data and raw data respectively.

Table 7: ANOVA table for hardness (S/N data)

\begin{tabular}{|lrrrrrrr|}
\hline Source & DF & Seq SS & Adj SS & Adj MS & F & P \\
\hline Spindle speed & 2 & 0.259194 & 0.259194 & 0.129597 & 155.49 & 0.000 \\
\hline Nelding speed & 2 & 0.207391 & 0.207391 & 0.103696 & 124.41 & 0.000 \\
\hline Residual Error & 4 & 0.003334 & 0.003334 & 0.000833 & & \\
\hline Total & 8 & 0.469919 & & & & \\
\hline S=0.02887 & R-Sq $=99.3 \%$ & R-Sq $(\operatorname{adj})$ & $=98.6 \%$ \\
\hline
\end{tabular}


Table 8: ANOVA table for hardness (raw data)

\begin{tabular}{|lrrrrrr|}
\hline Source & DF & Seq SS & Adj SS & Adj MS & F & P \\
\hline Spindle speed & 2 & 17.2794 & 17.2794 & 8.63968 & 158.98 & 0.000 \\
\hline Welding speed & 2 & 13.7868 & 13.7868 & 6.89341 & 126.85 & 0.000 \\
\hline Residual Error & 4 & 0.2174 & 0.2174 & 0.05434 \\
\hline Total & 8 & 31.2836 & & & \\
\hline S $=0.2331 \quad$ R-Sq $=99.38$ & R-Sq (adj) $=98.68$ \\
\hline
\end{tabular}

Table 9: Response table for hardness ( $\mathrm{S} / \mathrm{N}$ ratio data, Larger-the-better)

\begin{tabular}{|lrr|}
\hline & Spindle & Welding \\
\hline Level & speed & speed \\
\hline 1 & 36.80 & 36.81 \\
\hline 2 & 36.94 & 36.95 \\
\hline 3 & 37.21 & 37.18 \\
\hline Delta & 0.41 & 0.37 \\
\hline Rank & 1 & 2 \\
\hline
\end{tabular}

Table 10: Response table for hardness (raw data)

\begin{tabular}{|c|c|c|}
\hline \multicolumn{3}{|c|}{ Response Table for Means } \\
\hline & Spindle & Welding \\
\hline Level & speed & speed \\
\hline 1 & 69.21 & 69.30 \\
\hline 2 & 70.30 & 70.44 \\
\hline 3 & 72.54 & 72.30 \\
\hline Delta & 3.33 & 3.00 \\
\hline Rank & 1 & 2 \\
\hline
\end{tabular}

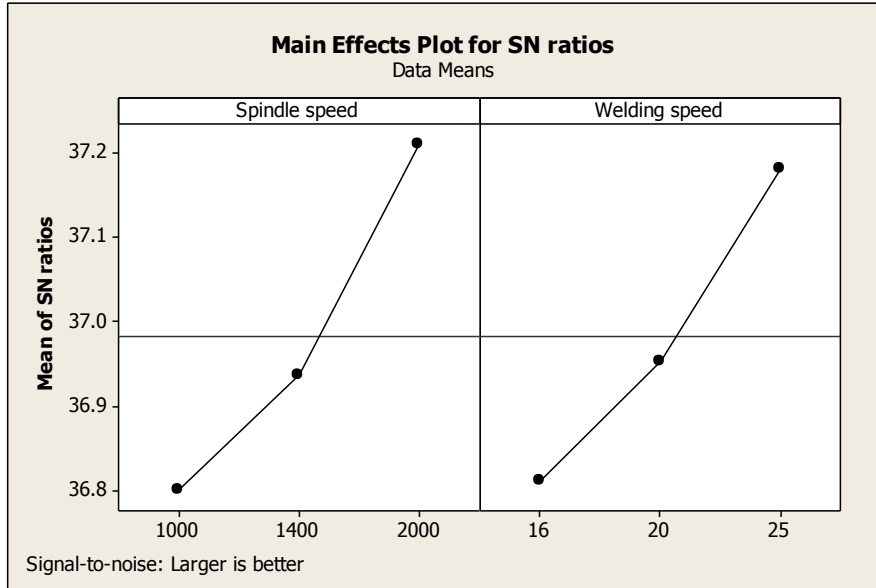

Figure 6: Effect of input parameters on hardness (S/N data) 


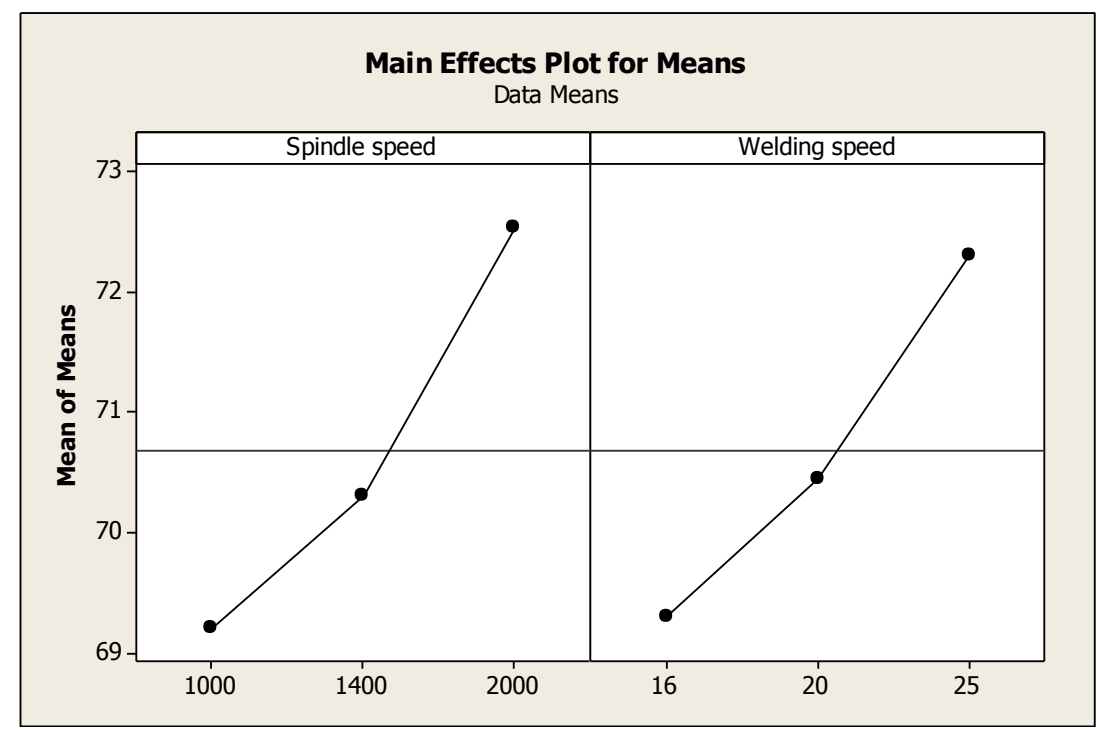

Figure 7: Effect of input parameters on hardness (raw data)

From figure 4 and 5 it can be concluded that for achieving maximum hardness the optimal setting is spindle speed of $2000 \mathrm{rpm}$ and welding speed of $25 \mathrm{~mm} / \mathrm{min}$.

\section{Conclusions}

Present study emphasis on investigating the optimal set of process parameters for maximizing ultimate tensile strength and hardness during friction stir welding of HE 30 and HE 9 aluminium alloy. Based on the experimental results and statistical analysis it was found that spindle speed and welding speed are significant process parameters that influence ultimate tensile strength and hardness. It was found that the actual value of ultimate tensile strength is higher at spindle speed of $1000 \mathrm{rpm}$ and welding speed of $20 \mathrm{~mm} / \mathrm{min}$. The hardness value which is calculated in terms of BHN is higher at spindle speed of $2000 \mathrm{rpm}$ and welding speed of $25 \mathrm{~mm} / \mathrm{min}$. Based on the experimental results it can be concluded that Taguchi method helps to find out optimal setting of process parameters in minimum number of experimental runs.

\section{References}

[1] Squillace A., Segreto T., Prisco U., Teti R., Campanile G. 2006, Optimization of friction stir welds of aluminum alloys, Second IPROMS NoE Virtual International Conference on Intelligent Production Machines and Systems.

[2] Meng Z., Chen H., Yue X. 2006, Knowledge Enterprise: Intelligent Stratagies In Product Design, Manufacturing, and Management, Proceedings of PRO LAM AT 2006, IFIP TC5 International Conference, June 15-17, Shanghai, China. 
[3] Fratini L., Corona V. (2007), Friction stir welding lap joint resistance optimization through gradient techniques. Journal of Manufacturing Science and Engineering-Transactions of the ASME, 129(6) 985-990.

[4] Nandan R., Lienert T. J., Roy T. D. (2008), Toward reliable calculations of heat and plastic flow during friction stir welding of Ti-6Al-4V alloy, International Journal of Materials Research, 99(4) 434-444.

[5] Okuyucu, H., Kurt, A., and Arcaklioglu, E. (2007), Artificial neural network application to the friction-stir welding of aluminum plates. Materials and Design, 28(1) 78-84.

[6] Lakshminarayanan, A. K., Balasubramanian, V. (2008), Process parameters optimization for friction stir welding of RDE-40 aluminium alloy using Taguchi technique, Transactions of Nonferrous Metals Society of China, 18(3) 548-554.

[7] Jayaraman M., Sivasubramanian R., Balasubramanian V., Lakshmi narayanan A.K. (2009), Optimization of process parameters for friction stir welding of cast aluminium alloy A319 by Taguchi method, Journal of Scientific and Industrial Research, 68(1) 36-43.

[8] R. Roy, Design of Experiments using the Taguchi approach- 16steps to product and process improvement, John Wiley and Son Inc, 2001.

[9] Phadke M.S., Quality Engineering using Robust Design, P T R Prentice Hall, New Jersey, 
